\title{
O RECONHECIMENTO DO REGIME DE COMPETÊNCIA DO CRÉDITO TRIBUTÁRIO DE ACORDO COM AS NORMAS BRASILEIRAS DE CONTABILIDADE.
}

\section{CREDIT RACING RULES OF RECOGNITION TAX IN ACCORDANCE WITH THE RULES ACCOUNTING BRAZILIAN.}

\section{RESUMO}

A Contabilidade Pública passou por mudanças oriundas das Normas Brasileiras de Contabilidade Aplicadas ao Setor Público de acordo com os padrões internacionais. O presente estudo teve como objetivo analisar a relevância da adoção do regime de competência para o reconhecimento dos créditos tributários na Prefeitura Municipal de Fortaleza, através do método de estudo de caso, com a utilização da abordagem qualitativa. Foi realizada uma entrevista semiestruturada, pois cada ente da federação possui práticas conceituais. O IPTU foi o único tributo reconhecido pelo regime de competência no Município de Fortaleza, e seus efeitos só poderão ser analisados no longo prazo.

Palavras-chave: Contabilidade pública, Regime de competência, Crédito tributário

\begin{abstract}
The Public Accounting underwent changes resulting from the Brazilian Accounting Standards Applied to the Public Sector in accordance with international standards. This study aimed to analyze the relevance of the adoption of the accrual basis for the recognition of tax credits in the City of Fortaleza, through the case study method, using a qualitative approach. A semi-structured interview was conducted, for each level of government has conceptual practices. The property tax is the only tax recognized on an accrual basis in the city of Fortaleza, and its effects can only be analyzed in the long run.
\end{abstract}

Keywords: Public accounting, Accrual method, Tax credit

\footnotetext{
${ }^{1}$ Mestre em Controladoria pela Universidade de São Paulo - USP. São Paulo - SP, Brasil. E-mail: indexlaw.ojs.hotmail.com

2 Especialista em Responsabilidade Civil pela Universidade de Fortaleza - UNIFOR - CE, Ceara, Brasil.

E-mail: indexlaw.ojs@hotmail.com
} 


\section{INTRODUÇÃO}

A Contabilidade Pública passa por um momento de mudanças tornando-se relevante analisar a adoção do Regime de Competência no reconhecimento dos créditos tributários, tendo como fundamentação as Normas Brasileiras de Contabilidade Aplicadas ao Setor Público (NBCASP), que busca a melhoria e qualidade da informação contábil e a transparência das ações governamentais, além de ser uma medida essencial para implantação dos sistemas de apuração de custos e de avaliação do desempenho da gestão pública.

O Processo de convergência às NBCASP no Brasil é representado de maneira operacional a partir do ano de 2008, quando foi emitida a $1^{\mathrm{a}}$ edição do Manual de Contabilidade Aplicada ao Setor Público (MCASP), que se encontra na sua $6^{\text {a }}$ edição após várias revisões.

Segundo Feijó (2013), a busca da sociedade contemporânea por transparência nas contas públicas exige informações confiáveis que reflitam a real situação patrimonial. A Contabilidade auxilia a instrumentalização do controle social, pois se trata de uma ciência social aplicada cujo principal objetivo é fornecer informações sobre resultados econômicos, financeiros e patrimoniais aos usuários, no sentido de contribuir para a tomada de decisões e adequada prestação de contas.

O crédito tributário é um direito do Estado decorrente do recolhimento dos tributos. São benefícios econômicos ou serviços potenciais compulsoriamente devidos às entidades do setor público, estabelecidos por leis para gerar receita para o Estado, com o intuito de financiar suas despesas conforme as Instruções de Pronunciamentos Contábeis 02 (IPC 02). Desta forma esse direito deve ser evidenciado no patrimônio.

A Portaria MF no 184/08 estabelece a uniformização dos procedimentos contábeis possibilitando a disponibilização de informações contábeis transparentes e comparáveis, que sejam compreendidas por analistas, financeiros, investidores, auditores, contabilistas e demais usuários, independentemente de sua origem e localização.

Este estudo busca responder a seguinte indagação: Qual a relevância do reconhecimento do crédito tributário do Imposto Sobre a Propriedade Predial e Territorial no Município de Fortaleza pelo Regime de Competência em conformidade com as Normas Brasileiras de Contabilidade Aplicada ao Setor Público?

Para atender a questão têm-se como objetivo geral deste estudo analisar o mecanismo de reconhecimento do crédito tributário do IPTU pelo Regime de Competência em 
conformidade com as Normas Brasileiras de Contabilidade aplicada ao Setor Público e como objetivos específicos: verificar os impactos significativos na estrutura patrimonial decorrentes da adoção do regime de competência no reconhecimento dos créditos tributários municipais; identificar as dificuldades encontradas pelos gestores e contadores públicos do Município de Fortaleza para o reconhecimento dos fatos seguindo o princípio da competência; e evidenciar a importância da adequação da transparência da informação no setor público.

Com o intuito de atender os objetivos expostos, foi realizada uma pesquisa exploratória, para que fossem obtidas as informações mais relevantes a respeito do tema, para tanto, foi realizada uma pesquisa bibliografia e documental, com foco em um estudo de caso realizado da Secretaria Municipal das Finanças do Município de Fortaleza (SEFIN), no período de 2013 a 2015, comparativamente.

Este artigo está estruturado da seguinte forma: na primeira seção a introdução, a segunda o referencial teórico que discorre a respeito do Imposto Sobre a Propriedade Predial e Territorial Urbana (IPTU), das Normas Brasileiras de Contabilidade Aplicadas ao Setor Público, Princípio da Competência e Estudos Anteriores. Na terceira seção, metodologia da pesquisa e como foi realizada a coleta dos dados. Em sua quarta seção, a análise dos dados. E na última encontram-se as considerações finais, seguida das referências bibliográficas.

\section{REFERENCIAL TEÓRICO}

\subsection{Normas Brasileiras de Contabilidade aplicadas ao setor público}

Para que seja possível entender a importância da harmonização internacional das normas de Contabilidade é necessário entender que essa busca por uma gestão pública mais eficiente, assim como transparente foi determinante no processo de convergência. Sousa et al. (2013), explicitam que as demonstrações contábeis estão passando por essa adaptação as normas contábeis internacionais, tendo em vista suprir uma carência existente na elaboração das demonstrações.

No Brasil, a adequação às práticas contábeis foi discutida no âmbito do Conselho Federal de Contabilidade (CFC). Para isso, foi criado um Comitê Gestor de Convergência, que qual tem o propósito de desenvolver ações para difundir a harmonização das Normas Brasileiras de Contabilidade.

Segundo Feijó (2013), poucos são os recursos e a população está cada vez mais ciente do papel do Estado e exige deste uma melhoria constante dos serviços públicos, assim como, uma melhor aplicação dos tributos pagos pelos contribuintes. Desta forma, exige-se que a Contabilidade gere informações relevantes para que auxilie no aumento da eficiência, economicidade e efetividade dos serviços. 
Deve-se evidenciar o conceito dado por Marion (2009) a Patrimônio, onde ele o define como o objeto da Contabilidade onde são utilizados métodos desenvolvidos de modo a considerar todas as ocorrências que venham a alterar a situação patrimonial, sendo essas informações de vital importância para a tomada de decisão dos gestores e para a melhoria da gestão pública.

Lima, Santana e Guedes (2009) fizeram um comparativo entre as Leis $n^{\circ} .4320 / 64$ e nº 101/00 e as Normas Brasileiras de Contabilidade Aplicadas ao Setor Público (NBCASP), para analisar a aderência da legislação vigente aos parâmetros contábeis de evidenciação, mensuração e reconhecimento presentes na teoria contábil. Esse estudo mostrou que mesmo apesar de ser importante para a legislação contábil pública brasileira a Lei nº. 4320/64 e a Lei de Responsabilidade Fiscal (LRF) não incorporaram em sua essência os fundamentos da teoria contábil.

No entanto as normas conforme Darós e Pereira (2009) trazem fatos relevantes para a Contabilidade Pública, como previsão de depreciação, adoção do regime de competência para receitas e despesas, contabilização dos bens de uso comum e relatórios de fluxo de caixa. Estes pontos contribuem para que o foco das informações contábeis não esteja estritamente relacionado à execução dos orçamentos públicos, mas também aos aspectos referentes ao patrimônio.

É importante destacar que, apesar de se enfocar o orçamento como propulsor do equilíbrio das finanças públicas no Brasil, em virtude de diversas interpretações direcionadas apenas para os conceitos orçamentários, dá-se pouca relevância para as alterações que impactam no patrimônio, apesar da Lei nº . 4.320/64 já discorrer nos arts. 85, 89, 100 e 104 do Título IX, a sua preocupação com as informações patrimoniais:

Art. 85. Os serviços de contabilidade serão organizados de forma a permitirem o acompanhamento da execução orçamentária, o conhecimento da composição patrimonial, a determinação dos custos dos serviços industriais, o levantamento dos balanços gerais, a análise e a interpretação dos resultados econômicos e financeiros Art. 89. A contabilidade evidenciará os fatos ligados à administração orçamentária, financeira patrimonial e industrial.

Art. 100 As alterações da situação líquida patrimonial, que abrangem os resultados da execução orçamentária, bem como as variações independentes dessa execução e as superveniências e insubsistência ativas e passivas, constituirão elementos da conta patrimonial.

Art. 104. A Demonstração das Variações Patrimoniais evidenciará as alterações verificadas no patrimônio, resultantes ou independentes da execução orçamentária, e indicará o resultado patrimonial do exercício (grifo nosso) (BRASIL, 2015).

No ano 2013, foi emitida a Portaria $n^{\circ}$. 634/13, exigindo a adoção do Plano de Contas Aplicado ao Setor Público (PCASP) e as Demonstrações Contábeis Aplicadas ao Setor Público (DCASP) que deveriam ser utilizados por todos os entes da Federação até o final do 
exercício de 2014. Os demais Procedimentos Contábeis Patrimoniais, exigidos no Manual de Contabilidade Aplicado ao Setor Público (MCASP), teriam o prazo final de implementação estabelecido de forma gradual por meio de ato normativo da Secretaria do Tesouro Nacional (STN), que é a responsável por direcionar os procedimentos para a gestão pública.

O Quadro 1 mostra as onze normas vigentes aplicáveis à Administração Pública, onde, se observa que as normas seguem uma lógica gradual de entendimento que vai da parte conceitual a procedimentos mais técnicos.

Quadro 1. Normas Brasileiras de Contabilidade Aplicada ao Setor Público.

\begin{tabular}{|c|c|l|}
\hline NUMERAÇÃ̃O & $\begin{array}{c}\text { CFC } \\
\text { RESOLUÇÃO }\end{array}$ & \multicolumn{1}{|c|}{ NORMA } \\
\hline NBC T 16.1 & $1.128 / 08$ & Conceituação, Objeto e Campo de Aplicação \\
\hline NBC T 16.2 & $1.129 / 08$ & Patrimônio e Sistemas Contábeis \\
\hline NBC T 16.3 & $1.130 / 08$ & Planejamento e seus Instrumentos sob o Enfoque Contábil \\
\hline NBC T 16.4 & $1.131 / 08$ & Transações no Setor Público \\
\hline NBC T 16.5 & $1.132 / 08$ & Registro Contábil \\
\hline NBC T 16.6 & $1.133 / 08$ & Demonstrações Contábeis \\
\hline NBC T 16.7 & $1.134 / 08$ & Consolidação das Demonstrações Contábeis \\
\hline NBC T 16.8 & $1.136 / 08$ & Controle Interno \\
\hline NBC T 16.9 & $1.137 / 08$ & Depreciação, Amortização e Exaustão \\
\hline NBC T 16.10 & $1.138 / 08$ & $\begin{array}{l}\text { Avaliação e Mensuração de Ativos e Passivos em Entidades } \\
\text { do Setor Público }\end{array}$ \\
\hline NBC T 16.11 & $1.366 / 11$ & Sistema de Informação de Custos do Setor Público \\
\hline
\end{tabular}
Fonte: Conselho Federal de Contabilidade (2012).

Segundo o Manual de Contabilidade Aplicado ao Setor Público, as NCASP, expedidas pela Secretaria do Tesouro Nacional (STN) são um grande marco para a Contabilidade Pública no Brasil, pois representam a padronização e a convergência dessa importante ferramenta de gerência pública aos modelos internacionais.

\subsection{Princípio da Competência aplicado ao setor público}

Reis (2006) analisa os regimes de caixa e de competência, utilizando-se do exame de normativos emitidos pela Secretaria do Tesouro Nacional (STN), Confederação Nacional dos Municípios (CNM), Lei $n^{\circ}$. 4.320/64 e Lei Complementar $n^{\circ}$. 101/00. O autor chegou a constatação que a adoção do regime de competência tende a beneficiar a administração das entidades governamentais, porque possibilita maiores mecanismos de controle e evidenciação da situação econômico-financeira do ente governamental, e ressalta que o regime de caixa tem provocado distorções nas receitas governamentais, em virtude de não possibilitar a visualização integral do seu volume no exercício. 
Desta forma, o fato de registrar o crédito tributário no momento que ocorre é mencionado no International Public Sector Accounting Standards - IPSAS 23 (2010), “[...] 
uma entidade deve reconhecer um ativo em relação a tributos quando o evento tributável ocorre e os critérios de reconhecimento do ativo são satisfeitos".

O Conselho Federal de Contabilidade publicou em maio de 2010, a Resolução CFC $n^{\circ} .1 .282 / 10$, que altera a Resolução CFC nº. 750/93 permanecendo, contudo, que a competência, como Princípio de Contabilidade, determina que os efeitos das transações e outros eventos sejam reconhecidos no período a que se referem, independentemente do recebimento ou pagamento.

No Quadro 2 é possível perceber a diferença da evidenciação do crédito tributário no momento da arrecadação e no momento do seu registro evidenciando como era feito esse reconhecimento do IPTU.

Quadro 2. Regimes da contabilidade aplicada ao setor público

\begin{tabular}{|c|c|c|c|c|c|}
\hline \multicolumn{3}{|c|}{ Regime Orçamentário } & \multicolumn{2}{c|}{ Regime Contábil (Patrimonial) } \\
\hline $\begin{array}{c}\text { Receita } \\
\text { Orçamentária }\end{array}$ & Arrecadação & $\begin{array}{c}\text { Lei n } \\
4.320 / 1964 \\
\text { art. 35 }\end{array}$ & $\begin{array}{c}\text { Variação } \\
\text { Patrimonial } \\
\text { Aumentativa }\end{array}$ & Competência & $\begin{array}{c}\text { Resolução } \\
\text { CFC n }\end{array}$ \\
$750 / 1993$ \\
\hline
\end{tabular}

Fonte: Elaborado pelo autor (2015).

De acordo com a Resolução CFC $n^{\circ}$. 1.282/10, quando ocorrido o fato gerador, pode-se proceder ao registro contábil do direito a receber em contrapartida de variação patrimonial aumentativa, o que representa o registro da variação patrimonial aumentativa por competência.

A implantação do regime de competência pode ser justificada no conceito de Patrimônio e suas variações aumentativas e diminutivas (receita e despesa sob o enfoque patrimonial). As Normas Brasileiras de Contabilidade Aplicadas ao Setor Público, NBC T 16.2 e NBC T 16.4, definem respectivamente patrimônio público e variações patrimoniais:

Item 3. Conjunto de bens e direitos, tangíveis e intangíveis, onerados ou não, adquiridos, formados, produzidos, recebidos, mantidos ou utilizados pelas entidades do Setor Público, que seja portador ou represente um fluxo de benefícios futuros, presente ou futuro, inerente à prestação de serviços públicos ou à exploração econômica por entidades do setor público e suas obrigações. (NBC T 16.2)

Item 4. As variações patrimoniais são transações que promovem alterações nos elementos patrimoniais da entidade do setor público, mesmo em caráter compensatório, afetando, ou não, o seu resultado. (NBC T 16.4)

Através orientações das Instruções de Pronunciamentos Contábeis 02, os ganhos com a adoção do regime de competência são refletidos em benefícios para a sociedade, na medida em que as informações subsidiam na tomada de decisão pelo gestor, propiciando 
reduções de custos e melhor alocação dos recursos públicos, bem como a instrumentalização do controle social e melhorias nos processos de prestação de contas e no controle exercidas pelos tribunais, órgãos de controle e pela sociedade.

\subsection{Tributo}

Diante da necessidade do homem viver em sociedade nasceu o Estado, que é uma entidade de força superior, que necessita de recursos financeiros para alcançar a sua finalidade de proporcionar o bem comum. O art. 173 da Constituição Federal Brasileira de 1988(CF/88) estabelece que “[...] não é próprio do Estado exercer atividade econômica, salvo quando isto é necessário para a segurança nacional, pois esta atividade é reservada ao setor privado".

Machado (2014, p. 24), salienta que “[...] o Estado exercita apenas atividade financeira, como tal entendido o conjunto de atos que o Estado pratica na obtenção, na gestão e na aplicação dos meios de pagamento de que necessita para atingir seus fins". Machado acrescenta que "[...] sendo o Estado uma entidade soberana, onde soberania é caracterizada como a vontade superior às vontades individuais e no exercício de sua autoridade o Estado impõe que os indivíduos lhe forneçam os recursos necessários".

$\mathrm{O}$ art. $3^{\circ}$, da Lei $\mathrm{n}^{\mathrm{o}} 5.172$, de 25 de outubro de 1966, o Código Tributário Nacional (CTN), define tributo como "toda prestação pecuniária compulsória, em moeda ou cujo valor nela se possa exprimir, que não constitua sanção de ato ilícito, instituída em lei e cobrada mediante atividade administrativa plenamente vinculada".

Carvalho (2013) explica que a expressão “[...] prestação pecuniária compulsória” têm o intuito de ressaltar a obrigatoriedade do pagamento do tributo, em moeda nacional, afastando assim a possibilidade de quitação por meio de prestações voluntárias.

Um dos pontos fundamentais do tributo é a sua competência tributária, ou seja, a possibilidade de serem criados através de leis vinculados aos entes da federação. Como definido por Amaro (2014, p. 115) “[...] todos têm, dentro de certos limites, o poder de criar determinados tributos e definir seu alcance, obedecidos os critérios de partilha de competência estabelecidos pela Constituição". O CTN trata do tema nos artigos $6^{\circ}$ a $8^{\circ}$ :

Art. $6^{\circ}$ A atribuição constitucional de competência tributária compreende a competência legislativa plena, ressalvadas as limitações contidas na Constituição Federal, nas Constituições dos Estados e nas Leis Orgânicas do Distrito Federal e dos Municípios, e observado o disposto nesta Lei.

Parágrafo único. Os tributos cuja receita seja distribuída, no todo ou em parte, a outras pessoas jurídicas de direito público pertencerá à competência legislativa daquela a que tenham sido atribuídos. 
Art. $7^{\circ}$ A competência tributária é indelegável, salvo atribuição das funções de arrecadar ou fiscalizar tributos, ou de executar leis, serviços, atos ou decisões administrativas em matéria tributária, conferida por uma pessoa jurídica de direito público a outra, nos termos do $\S 3^{\circ}$ do artigo 18 da Constituição. (BRASIL, 2015)

Machado (2014) discorre que a vinculação entre o Estado e as pessoas sujeitas à tributação não é apenas uma relação de poder, trata-se de uma relação jurídica que surge a ocorrência de um fato previsto em uma norma com capacidade de produzir esse efeito, isso

decorre do princípio da legalidade, pois essa norma deverá ser uma lei em sentido restrito, salvo quando se trata de obrigação acessória.

A lei retrata um fato e atribui a este o efeito de criar uma relação entre alguém e o Estado, Amaro (2014, p. 281) esclarece que "[...] a obrigação tributária nasce à vista de fato previamente descrito, cuja ocorrência, cuja ocorrência tem a aptidão, dada por lei, de gerar aquela obrigação, este fato é denominado em direito tributário como fato gerador do tributo". O art. 114 do CTN se inicia estatuindo que o fato gerador da obrigação principal é a situação definida em lei como necessária e suficiente à sua ocorrência.

Como elementos constitutivos do laço obrigacional tributário, Carvalho (2013) discorre a respeito dos sujeitos, ativo e passivo dessa relação jurídica tributária, o sujeito ativo

é o titular do direito subjetivo de exigir a prestação do tributo, ou seja, o credor, o detentor da capacidade tributária, o art. 119 do CTN que dispõe a respeito da relação jurídica obrigacional, define que o "[...] sujeito ativo da obrigação tributária é a pessoa jurídica de direito público, titular da competência para exigir o seu cumprimento".

O outro sujeito da relação é o sujeito passivo é a pessoa física ou jurídica de que é exigido o pagamento da obrigação, o art. 121, parágrafo único da CTN, define que o sujeito passivo pode assumir como contribuinte, quando possui relação pessoal e direta com o fato gerador. Em alguns casos, também pode assumir como responsável, quando não se trata de um contribuinte, mas a sua obrigação é decorrente de lei.

\subsection{Imposto Sobre a Propriedade Predial e Territorial Urbana (IPTU)}

A Constituição Federal de 1988, no art. 156, inciso I e o Código Tributário Nacional (CTN), art. 32, instituem que é de competência dos municípios a tributação do Imposto Sobre a Propriedade Predial e Territorial Urbana (IPTU), essa competência tributária é concedida pela $\mathrm{CF} / 88$ aos entes federativos, para que eles criem, instituam,fixem alíquotas máximas e mínimas e regulem os tributos. É valido ressaltar que 
essa competência é "indelegável" de acordo com o CTN, art. $7^{\circ}$, logo os municípios são sujeitos da obrigação tributária.

O IPTU tem por fato gerador o disposto no art. 32 do CTN, é importante mencionar que só existirá a cobrança do imposto caso sejam preenchidos pelo menos dois requisitos dos contidos no $\S 1^{\circ}$ :

\footnotetext{
Art. 32. O imposto, de competência dos Municípios, sobre a propriedade predial e territorial urbana tem como fato gerador a propriedade, o domínio útil ou a posse de bem imóvel por natureza ou por acessão física, como definido na lei civil, localizado na zona urbana do Município.

$\$ 1^{\circ}$ - Para os efeitos deste imposto, entende-se como zona urbana a definida em lei municipal; observado o requisito mínimo da existência de melhoramentos indicados em pelo menos 2 (dois) dos incisos seguintes, construídos ou mantidos pelo Poder Público:

I - meio-fio ou calçamento, com canalização de águas

pluviais; II - abastecimento de água;

III - sistema de esgotos sanitários;

IV - rede de iluminação pública, com ou sem posteamento para distribuição domiciliar;

V - escola primária ou posto de saúde a uma distância máxima de 3 (três) quilômetros do imóvel considerado.(BRASIL, 2015)
}

O sujeito passivo do IPTU segundo Harada (2012) é aquela pessoa física ou jurídica detentora da disponibilidade econômica do imóvel, pois somente o fato de ser possuidora do bem não faz com que ela preencha o requisito do aspecto material ou nuclear do fato gerador do IPTU.

É necessário que o contribuinte do devido imposto reúna os três atributos da propriedade, que são: "a faculdade de usar, gozar e dispor da coisa", de acordo com o art. 1.228 do Código Civil brasileiro de 2002. Deve ser levado em conta que o "[...] contribuinte do imposto será o proprietário do imóvel, o titular do seu domínio útil ou ainda o seu possuidor a qualquer título", nos termos do art. 34 do CTN.

Esse tributo, segundo o art. 33 do CTN tem como “[...] base de cálculo do imposto o valor venal do imóvel", que é o produto do somatório do valor do terreno com o valor atribuído à edificação. Para determinação dessa base, o administrador municipal calcula uma estimativa do preço razoável do imóvel nas condições de mercado, tendo em vista os atributos registrados no cadastro imobiliário da prefeitura, conforme art. 33 do CTN.

Art. 33. A base do cálculo do imposto é o valor venal do imóvel.

Parágrafo único. Na determinação da base de cálculo, não se considera o valor dos bens móveis mantidos, em caráter permanente ou temporário, no imóvel, para efeito de sua utilização, exploração, aformoseamento ou comodidade. (BRASIL, 2015) 
Define-se como alíquota um “[...] indicador numérico, da proporção do tributo com relação à expressão de riqueza. Geralmente, a alíquota apresenta-se como uma cifra percentual" (FERNANDES, 2002, p. 51).

Segundo Bones (2006), a Constituição Federal vigente não faz qualquer restrição quanto ao estabelecimento das alíquotas do IPTU, não prevê qualquer limite, revestindose, portanto, o legislador municipal, de grande autonomia, pois tem a competência para a fixação das mesmas.O IPTU é caracterizado como fiscal pois é uma fonte de arrecadação municipal, mas também possui caráter extrafiscal, em conformidade com a $\mathrm{CF} / 88$, inciso II; do $\S 4^{\circ}$, do art. 182 .

Art. 182. A política de desenvolvimento urbano, executada pelo Poder Público municipal, conforme diretrizes gerais fixadas em lei, tem por objetivo ordenar o pleno desenvolvimento das funções sociais da cidade e garantir o bem-estar de seus habitantes. (...)

$\S 4^{\circ}$ É facultado ao Poder Público municipal, mediante lei específica para área incluída no plano diretor, exigir, nos termos da lei federal, do proprietário do solo urbano não edificado, subutilizado ou não utilizado, que promova seu adequado aproveitamento, sob pena, sucessivamente, de: (...)

II - imposto sobre a propriedade predial e territorial urbana progressivo no tempo.(BRASIL, 2015)

Com isso a CF/88 autoriza a utilização do IPTU como um disciplinador da ocupação urbana, buscando assim desestimular a sua má ocupação evidenciando assim a sua função extrafiscal.

As hipóteses de isenção do IPTU são instituídas através de Lei Complementar $\mathrm{n}^{\circ}$ 159, de 23 de dezembro de 2013 do Município de Fortaleza, conforme art. 114 existe benefício fiscal nos seguintes casos:

Art. 114. A isenção, ainda quando prevista em contrato, é sempre decorrente de lei específica que estabeleça as condições e requisitos exigidos para a sua concessão, os tributos a que se aplica e, sendo caso, o prazo de sua duração. $\S 1^{\circ} \mathrm{A}$ isenção pode ser restrita a determinada região ou bairro do território do Município, em função de condições a ela peculiares.

$\S 2^{\circ}$ A concessão de isenção tributária é condicionada à adimplência do beneficiário com as obrigações tributárias principais e acessórias de sua responsabilidade, até a data da aplicação do benefício fiscal e, a continuidade do benefício, à permanência da adimplência com as obrigações tributárias não abrangidas pela isenção.

$\S 3^{\circ}$ A concessão de isenção e o seu reconhecimento, salvo disposição expressa, não afasta a obrigatoriedade de cumprimento das obrigações acessórias e dos deveres de substituto e responsável tributário previstos na legislação tributária. (BRASIL, 2015)

Sobre a imunidade do IPTU do Município de Fortaleza, o art. $8^{\circ}$ da Lei

Complementar $\mathrm{n}^{\circ}$ 159/13 institui: 
Art. $8^{\circ}$ É vedado ao Município instituir e cobrar impostos sobre: I - o patrimônio e os serviços da União Federal, dos estados, do Distrito Federal e dos municípios; II - os templos de qualquer culto;

III - o patrimônio e os serviços dos partidos políticos, inclusive suas fundações, das entidades sindicais dos trabalhadores, das instituições de educação e de assistência social, sem fins lucrativos, que atendam aos seguintes requisitos:

a) mantiverem escrituração de suas receitas e despesas em livros revestidos de formalidades capazes de assegurar sua exatidão;

b) não distribuírem qualquer parcela de seu patrimônio ou de suas rendas, a qualquer título;

c) aplicarem integralmente, no País, os seus recursos na manutenção dos seus objetivos institucionais;

IV - livros, jornais, periódicos e o papel destinado a sua impressão;

$\mathrm{V}$ - fonogramas e videofonogramas musicais produzidos no Brasil contendo obras musicais ou literomusicais de autores brasileiros e/ou obras em geral interpretadas por artistas brasileiros, bem como os suportes materiais ou arquivos digitais que os contenham, salvo na etapa de replicação industrial de mídias ópticas de leitura a laser. (BRASIL, 2015)

Apesar de haver um paralelismo entre a Isenção e a Imunidade justificado pelo fato de que em ambas inexiste o dever prestacional tributário, Carvalho (2013) menciona que muitos escritos da dogmática jurídica tributária brasileira tratam essas duas realidades normativas de forma conjunta objetivando mostrar seus pontos de similitude, sendo que isso se mostrará equivocado, pois como explicitado por Machado (2014), a isenção é configurada

como uma exceção à regra jurídica de tributação, enquanto que no caso da imunidade a tributação está proibida por regra constitucional que impede a sua incidência.

\subsection{Estudos Anteriores}

Para Zarth (2010) a Contabilidade aplicada ao Setor Público deve fornecer as informações necessárias à tomada de decisões, à prestação de contas e os instrumentos para o controle social, como previsto normativamente. Ele acredita que para atingir esses objetivos, a informação contábil deve fundamentar-se em um sistema que permita a adequada mensuração do patrimônio e do resultado dos entes governamentais. Logo, o correto tratamento das despesas e receitas propiciaria maior confiabilidade aos resultados obtidos pelo governo. E, portanto, para a correta apuração do resultado do exercício pelo regime de competência. Seria necessário o devido registro e tratamento das despesas e receitas pelo enfoque patrimonial, independentemente do tratamento orçamentário.

Beuren e Sothe (2009) analisou os impactos das mudanças no reconhecimento e mensuração decorrentes da alteração do regime misto para o regime de competência proposto pelo Estudo n. ${ }^{\circ} 14$ do International Federation of Accountants (IFAC) de 2011 nas contas públicas dos governos municipais da microrregião de São Miguel do Oeste (SC). Utilizando-se das demonstrações contábeis e relatórios dos departamentos 
administrativos dos governos de cinco municípios, nos exercícios de 2004 a 2008, o autor concluiu que os impactos provenientes das mudanças no reconhecimento e mensuração da alteração do regime misto para o regime de competência foram significativos na estrutura do Ativo Circulante.

Cruvinel e Lima (2011) tiveram como meta analisar a adoção do regime contábil de competência pelo setor público brasileiro sob a visão das NBCASP e das IPSAS, por meio de pesquisa bibliográfica e documental. Foram utilizados também os normativos legais da STN, Tribunal de Contas da União (TCU) e Procuradoria Geral da Fazenda Nacional (PGFN).

Os autores relatam ainda que as NBCASP buscam a competência integral, e o MCASP objetiva tornar compatível a visão orçamentária com a visão patrimonial. Salientam ainda que, em virtude do regime misto adotado pela Lei n. ${ }^{\circ}$ 4.320/64 e da necessidade de revisá-la, pode haver dificuldades na adoção do regime de competência no Brasil. Com relação às IPSAS, alertam para o fato de que a Contabilidade pública no Brasil vem evoluindo apenas nos registros orçamentários.

\section{PROCEDIMENTOS METODOLÓGICOS}

A metodologia definida para o presente estudo com relação aos seus objetivos é a pesquisa exploratória, pois segundo Gil (2010) as pesquisas exploratórias buscam proporcionar maior familiaridade com a questão problema, tornando-a mais compreensível. Este método foi escolhido considerando-se o fato de que a adoção do Regime de Competência para reconhecimento das Receitas no Setor Público, ainda está em fase de implantação.

Andrade, Maria e Lakatos (2010) menciona que a pesquisa exploratória é o ponto de inicial de todo trabalho científico, pois fornece as informações mais relevantes sobre determinado assunto, além de facilitar a formulação de temas, objetivos e hipóteses do trabalho.

Quanto ao objeto da pesquisa, aplica-se nesse artigo uma abordagem preponderantemente qualitativa para analisar as informações inferidas e sobre os conceitos aplicados. Raupp e Beuren (2010, p. 92) explicam que “[...] na pesquisa qualitativa concebem-se análises mais profundas em relação ao fenômeno que está sendo estudado". Ainda segundo Beuren pesquisa qualitativa destaca características não observadas por meio de um estudo quantitativo. 
Fez-se, precipuamente, uma pesquisa bibliográfica, constatando-se a escassez de estudos similares sobre a Aplicação do Regime de Competência no reconhecimento dos Créditos Tributários. GIL (2010) afirma que o estudo bibliográfico é desenvolvido a partir de materiais como livros e artigos científicos, e que a pesquisa documental possui muita similaridade com a bibliográfica, divergindo apenas na natureza das fontes, pois nesta são utilizados materiais que ainda não passaram por um processo analítico.

Posteriormente, realizou-se um estudo de caso na Secretaria de Finanças do município de Fortaleza, para que fossem evidenciados os benefícios e as dificuldades encontradas durante o processo de implantação do Regime de Competência, no caso específico da Receita de IPTU. Yin (2010, p.39) define estudo de caso como "[...] uma investigação empírica sobre um fenômeno contemporâneo em profundidade e em seu contexto de vida real, especialmente quando os limites entre o fenômeno e o contexto não são claros",

A coleta de dados foi realizada com a técnica de entrevista semiestruturada com quinze questões abertas com o Assessor Contábil da Prefeitura de Fortaleza, que coordenou o projeto de adequação às Normas brasileiras de Contabilidade Aplicadas ao Setor Público, com o foco na evidenciação do IPTU pelo regime de competência.

A técnica de análise utilizada foi a descritiva sobre as informações divulgadas no subgrupo do Ativo Circulante nos exercícios de 2013 e 2014, para que fossem comparadas as mudanças ocorridas em decorrência da adoção do regime de competência.

\section{ANÁLISE DE RESULTADOS}

Esta seção contém a análise dos dados e os resultados da pesquisa. Para uma melhor compreensão e organização deste estudo, os dados foram coletados através da análise documental e por meio de entrevista.

A primeira subseção evidencia o processo da adoção das Normas Brasileiras de Contabilidade no Setor Público em um sentido lógico que parte de uma breve explanação de como o núcleo de Contabilidade da Secretaria Municipal das Finanças de Fortaleza (SEFIN) está realizando a adequação para, posteriormente, se fazer o reconhecimento do IPTU pelo Regime de Competência. A seguir, serão evidenciados os resultados da entrevista realizada com o Assessor Contábil que faz parte da equipe responsável.

\subsection{Processo de Implantação das NBCASP no Município de Fortaleza}


Em toda administração pública nacional, o processo de implantação das NBCASP representa uma transformação significativa no setor de Contabilidade, pois contribui na elaboração de informações mais comparáveis e transparentes para os seus usuários.

Assim como toda mudança, o Município de Fortaleza teve diversas dificuldades no processo, conforme foram expostas na entrevista realizada com o Assessor Contábil do município. Foram mencionados os principais entraves gerais para essa transição: o tempo, um sistema que não possuía os mecanismos necessários para atender as exigências das normas e uma equipe com um pequeno número de colaboradores para realizar as adequações das informações.

Esse processo de transição no município teve início em 2013, possuindo um prazo curto para atender as determinações da Portaria STN nº. 634, de 12 de junho de 2012 e da Instrução Normativa TCM nº. 01/2014, sendo que essa instituía a adoção do Plano de Contas Aplicado ao Setor Público (PCASP) até o final de 2014.

Logo, para que essas determinações fossem atendidas, parte da equipe da célula de Contabilidade ficou responsável por adequar as práticas contábeis vigentes aos padrões exigidos, desenvolvendo a parte conceitual de um novo sistema a fim de criar uma estrutura capaz de atender as exigências da Secretaria do Tesouro Nacional.

Os profissionais envolvidos no processo foram qualificados, pois deveriam estar atualizados sobre as mudanças impostas pelas NBCASP, em virtude de envolver transformações na estrutura contábil das entidades, para tanto, o MCASP foi amplamente utilizado pela equipe. Para a Secretaria obter êxito no processo de transição foi necessário implantar um sistema informacional que suprisse a Contabilidade das informações necessárias

de forma analítica e tempestiva. Nesse período era utilizado o Sistema Integrado de Orçamento e Finanças (SIOF), mas sua estrutura não era capaz de suportar as alterações necessárias.

Visto isso, no ano de 2013 a equipe responsável pela implantação das NBCASP da Coordenadoria do Tesouro Municipal (COTEM), juntamente com a Coordenadoria de Gestão Estratégica da Tecnologia da Informação (CGETI) da SEFIN, com o auxílio do Instituto Federal de Tecnologia do Ceará (IFCE) iniciaram o desenvolvimento do Sistema de Gestão de Recursos e Planejamento de Fortaleza, Financeiro e Contábil (GRPFOR-FC), esse sistema foi entregue em outubro de 2014 completamente adequado para atender às Normas Brasileiras de Contabilidade Aplicada ao Setor Público. 
No ano de 2014 os dados utilizados para a elaboração do Balanço Geral do Município foram obtidos por meio de escrituração realizada pelos órgãos e entidades da administração direta e indireta ainda feita no SIOF, no período de janeiro a setembro, e de outubro a dezembro no GRPFOR-FC, é relevante mencionar que os dados do SIOF foram importados para o novo sistema.

Vale ressaltar que a estrutura desse novo software foi uma importante ferramenta que possibilitou a elaboração das Demonstrações Contábeis de acordo com o novo padrão estabelecido no Manual de Contabilidade Aplicada a o Setor Público (MCASP) e a adequação das informações contábeis ao PCASP ampliando as formas de controle e geração de informações gerenciais.

\subsection{Processo inicial de Implantação do IPTU pelo Regime de Competência}

Com a utilização do GRPFOR-FC, a aplicação do PCASP e a interação dos Setores de Contabilidade e arrecadação foi possível o início do processo de reconhecimento dos créditos tributários pelo Regime de Competência, sendo que até o momento atual o IPTU é o único que está sendo mensurado dessa forma, devido a sua modalidade de lançamento, por ofício, que facilita a apuração dos seus valores.

De acordo com a Contabilidade da SEFIN para obedecer ao Princípio da Competência serão acrescentados alguns registros contábeis reconhecendo a existência dos valores a receber a que o município tem direito, que serão realizados no dia $1^{\circ}$ de janeiro, momento em que acontece o fato gerador da obrigação tributária, instituindo um direito a receber para o Município, sujeito ativo, e a obrigação a pagar para o contribuinte, sujeito passivo, diferentemente do que ocorre no Regime de Caixa, quando a existência dos Créditos a Receber só ocorrem no momento em que a arrecadação se concretiza.

Quadro 3. Lançamento do valor bruto

\begin{tabular}{|c|c|c|c|c|}
\hline Natureza da informação & Mov. & Código & Descrição & Conta Corrente \\
\hline \multirow{2}{*}{$\begin{array}{c}\text { Patrimonial, reconhecimento do } \\
\text { crédito tributário }\end{array}$} & $\mathrm{D}$ & 1.1 .2 .1 .1 .01 .05 .00 .00 .00 & IPTU & $\begin{array}{c}\text { Classificação da } \\
\text { receita }\end{array}$ \\
\cline { 2 - 5 } & $\mathrm{C}$ & 4.1 .1 .2 .1 .02 .00 .00 .00 .00 & IPTU & \\
\hline
\end{tabular}


Fonte: Secretaria das Finanças de Fortaleza (2015).

O primeiro e principal registro contábil que será escriturado logo após o lançamento do IPTU por ofício, consiste no reconhecimento do total dos Créditos Tributários de IPTU a receber que equivale ao valor total do IPTU referente aos imóveis cadastrados no Município.

Quadro 4. Lançamento das exclusões de créditos tributários

\begin{tabular}{|c|c|c|c|c|}
\hline Natureza da informação & Mov. & Código & Descrição & Conta corrente \\
\hline $\begin{array}{c}\text { Patrimonial reconhecimento da renúncia } \\
\text { da receita IPTU }\end{array}$ & $\mathrm{D}$ & 4.1 .1 .2 .1 .97 .10 .01 .00 .00 & $\begin{array}{c}(-) \\
\text { renúncia } \\
\text { IPTU }\end{array}$ & \\
\cline { 2 - 5 } & $\mathrm{C}$ & 1.1 .2 .1 .1 .01 .05 .00 .00 .00 & IPTU & $\begin{array}{c}\text { Classificação da } \\
\text { receita }\end{array}$ \\
\hline
\end{tabular}

Fonte: Secretaria das Finanças de Fortaleza (2015).

O Quadro 4 mostra o registro contábil dos valores referentes aos casos de isenção de IPTU conforme foram identificados no art. 113 da Lei Complementar $\mathrm{n}^{\circ} 159$, de 23 de dezembro de 2013. As isenções são espécies de renúncias de receitas, que o próprio ente estabelece com base em critérios próprios, esses critérios podem ser modificados de um exercício para outro.

Nos Quadros 5 e 6 estão os registros contábeis do Valor das Deduções referentes às Imunidades e aos Imóveis sem endereços.

Quadro 5. Lançamento das Deduções referentes a Imunidades

\begin{tabular}{|c|c|c|c|c|}
\hline Natureza da informação & Mov. & Código & Descrição & Conta corrente \\
\hline \multirow{2}{*}{$\begin{array}{c}\text { Patrimonial reconhecimento } \\
\text { das deduções da receita IPTU }\end{array}$} & D & 4.1 .1 .2 .1 .97 .01 .01 .00 .00 & $\begin{array}{c}\text { (-) deduções } \\
\text { imunidades - } \\
\text { IPTU }\end{array}$ & \\
\cline { 2 - 5 } & $\mathrm{C}$ & 1.1 .2 .1 .1 .01 .05 .00 .00 .00 & IPTU & $\begin{array}{c}\text { Classificação da } \\
\text { receita }\end{array}$ \\
\hline
\end{tabular}

Fonte: Secretaria das Finanças de Fortaleza (2015).

Este registro contábil com base nos casos de imunidade tributária segundo o art. $8^{\circ}$ do CTM. Diferentemente das renúncias de receita as Imunidades são garantias constitucionais e, portanto, inalteráveis pelos entes.

Quadro 6. Lançamento das Deduções referentes aos imóveis sem endereço

\begin{tabular}{|c|c|c|c|c|}
\hline Natureza da informação & Mov. & Código & Descrição & $\begin{array}{c}\text { Conta } \\
\text { corrente }\end{array}$ \\
\hline & & & (-) deduções &
\end{tabular}




\begin{tabular}{|c|c|c|c|c|}
$\begin{array}{c}\text { Patrimonial reconhecimento } \\
\text { das deduções da receita IPTU }\end{array}$ & $\mathrm{D}$ & $4.1 .1 .2 .1 .97 .01 .02 .00 .00-$ & $\begin{array}{c}\text { cadastro de } \\
\text { imóveis } \\
\text { incompleto - IPTU }\end{array}$ & \\
\cline { 2 - 5 } & $\mathrm{C}$ & 1.1 .2 .1 .1 .01 .05 .00 .00 .00 & IPTU & $\begin{array}{c}\text { Classificação } \\
\text { da receita }\end{array}$ \\
\hline
\end{tabular}

Fonte: Secretaria das Finanças de Fortaleza (2015).

Esse registro contábil é referente aos imóveis cujo cadastro não possuam informações suficientes pra que seja emitida a notificação do lançamento por ofício. Portanto como não houve o lançamento tributário, não gerou a obrigação do pagamento.

Quadro 7. Reconhecimento da receita por competência - lançamento anual em janeiro

\begin{tabular}{|c|c|c|c|c|}
\hline Natureza da informação & Mov. & Código & Descrição & Conta corrente \\
\hline $\begin{array}{c}\text { Patrimonial reconhecimento da } \\
\text { provisão de ajuste para perdas } \\
\text { em créditos }\end{array}$ & D & 3.6 .1 .7 .1 .01 .01 .00 .00 .00 & IPTU & \\
\cline { 2 - 5 } & $\mathrm{C}$ & 1.1 .2 .9 .1 .01 .01 .01 .00 .00 & $\begin{array}{c}\text { (-) perdas estimadas } \\
\text { em impostos - IPTU }\end{array}$ & $\begin{array}{c}\text { Classificação da } \\
\text { receita }\end{array}$ \\
\hline
\end{tabular}

Fonte: Secretaria das Finanças de Fortaleza (2015).

Esses registros contábeis referem- se às perdas de créditos tributários do IPTU que é uma média dos três últimos anos anteriores ao exercício corrente, estes registro serão realizados antes do momento da arrecadação e os seus resultados alimentarão a composição do grupo Créditos a receber que está contido no Balanço Patrimonial do município a partir do ano 2014, pois trata-se de um novo grupo trazido pelo PCASP.

Porém, como já foi mencionado, o único crédito tributário utilizado nesse cálculo foi o IPTU. Nos demonstrativos contábeis de 2013 essa informação não era evidenciada, conforme pode ser notado a partir da análise do Ativo Financeiro na Tabela 1.

Por meio do detalhamento da composição Créditos a Receber a Curto Prazo, que está em Notas Explicativas, é que se torna possível mensurar quanto o Município teria de direito a receber antes mesmo da efetiva arrecadação do crédito tributário.

Isso possibilita um controle dos valores que deixaram de ser arrecadados, para que a partir dessas informações possam ser tomadas as medidas necessárias para a melhoria da arrecadação municipal, sendo então, uma importante informação gerencial, pois antes a SEFIN não possuía esse alcance de forma exata.

Portanto, pode-se verificar na Tabela 1 que não existe evidenciação dos Créditos a Receber a Curto Prazo, estão embutido em ouras contas, podendo ser entendido apenas através das Notas Explicativas anexas aos Relatórios Contábeis.

Tabela 1. Ativo Financeiro de 2013 da Prefeitura Municipal de Fortaleza 


\begin{tabular}{|l|c|}
\hline DISPONÍVEL & $1.184 .475 .360,35$ \\
Bancos/Diretas & $45.714 .127,13$ \\
Bancos/Indiretas & $258.248 .521,09$ \\
Bancos c/Vinculada & $107.377 .707,15$ \\
Bancos/Câmara & $156.183,51$ \\
Bancos/IPM-PREVIFOR & $772.978 .821,47$ \\
REALIZÁVEL & $75.853 .589,56$ \\
Diversos Devedores & $52.527 .717,52$ \\
Diversos Devedores/IPM & $16.507 .284,77$ \\
Perdas Prováveis em Investimentos/IPM & $-16.507 .284,77$ \\
Debêntures de Valores Mobiliários & $23.325 .872,04$ \\
Total & $\mathbf{1 . 2 6 0 . 3 2 8 . 9 4 9 , 9 1}$ \\
\hline
\end{tabular}

Fonte: Adaptado da Prefeitura de Fortaleza (2013)

A Prefeitura de Fortaleza a partir do ano de 2014 passou a ser utilizado o PCASP nas demonstrações contábeis no Município de Fortaleza, logo incorporou aos Créditos a Receber, verificado na Tabela 2, o valor lançado e não arrecadado de IPTU referente ao exercício de 2014, posteriormente será iniciada a parametrização contábil para reconhecer os demais tributos pelo Regime de Competência e com isso buscou evidenciar o quanto a Secretaria Municipal das Finanças possui ainda pendente de arrecadação tributário do IPTU.

Tabela 2: Ativo Circulante de 2014 da Prefeitura Municipal de Fortaleza

\begin{tabular}{l|c}
\hline \multicolumn{1}{c|}{ ATIVO CIRCULANTE } & R\$ \\
\hline Caixa e Equivalentes de Caixa & $45.714 .127,13$ \\
Créditos a Receber à Curto Prazo & $142.862 .957,3$ \\
Investimentos e Aplicações Temporárias a CP & - \\
Estoques & $19.929 .249,84$ \\
VPD Pagas Antecipadamente & $270.114,95$ \\
Total & $\mathbf{1 . 4 6 7 . 6 8 0 . 0 4 5 , 4 7}$ \\
\hline
\end{tabular}

Fonte: Adaptado da Prefeitura de Fortaleza (2014).

Portanto, apenas à partir de 2014 que realmente foi visualizado nos Relatórios Contábeis as evidenciação das Contas a Receber à Curto Prazo referente ao IPTU.

\section{CONSIDERAÇÕES FINAIS}

Diante do contexto trazido para a Contabilidade Pública através das Normas Brasileiras de Contabilidade aplicadas ao Setor Público, o presente estudo teve como 
objetivo descrever como está ocorrendo o processo de adequação do Regime Patrimonial do Município

de Fortaleza ao reconhecimento do IPTU pelo Regime de Competência que introduziu neste uma nova forma de reconhecimento, mensuração e evidenciação desse crédito tributário.

Foi verificado que ocorreu um impacto significativo na estrutura patrimonial do Município, pois a partir do detalhamento dos Créditos a Curto Prazo é evidenciada a real capacidade tributária do ente e a partir dessa informação podem ser tomadas medidas para redução da perda dessa capacidade.

Observou-se que a SEFIN passou por muitas dificuldades para iniciar a implementação das NBCASP, como por exemplo, um sistema informacional defasado, que não possuía as ferramentas necessárias para a adequação das informações, uma equipe com poucos profissionais e um tempo curto para realizar a adequações dessas informações.

As dificuldades foram minimizadas com o desenvolvimento do Sistema de Gestão de Recursos e Planejamento de Fortaleza, Financeiro e Contábil (GRPFOR-FC), que foi entregue, em outubro de 2014, integralmente adaptado para atender às Normas Brasileiras de Contabilidade, além disso, outro ponto importante para a diminuição redução das dificuldades encontradas foi a qualificação da equipe envolvida no nesse processo, pois estes deveriam estar atualizados sobre as mudanças impostas pelas NBCASP, em virtude das modificações na estrutura contábil das entidades.

A partir dos resultados obtidos, percebeu-se que são inúmeros os ganhos informacionais em virtude da adoção do Regime de Competência. Esses registros possibilitarão o reconhecimento dos valores que deixaram de ser arrecadados, reduzirão fraudes fiscais, uma vez que, dão publicidade aos valores a serem pagos dificultando negociações fraudulentas para pagamento a menor dos valores devidos e ainda reduzirá as perdas por prescrição já que os valores serão inscritos em dívida automaticamente.

É importante ressaltar que a SEFIN está em um processo gradual de implantação dessas mudanças em seus registros patrimoniais e isso demanda tanto esforço por parte da equipe que o único tributo no qual é possível analisar atualmente em consonância com a IPC 02 é o IPTU.

\section{REFERÊNCIAS}


AMARO, L. Direito tributário brasileiro. 20. ed. São Paulo: Saraiva, 2014.

ANDRADE, M.; MARCONI, M. A.; LAKATOS, E. M. Fundamentos de metodologia científica: Técnicas de pesquisa 7. ed. São Paulo: Atlas, 2010.

BEUREN, I. M.; SÖTHE, A. A teoria da legitimidade e o custo político nas evidenciações contábeis dos governos estaduais da região sudeste do Brasil. Revista de Contabilidade e Organizações. São Paulo, v. 3, p. 98-120, n. 5. 2009.

BONES, T. F. F. A aplicação de alíquotas progressivas no IPTU.Revista Jus Navigandi, Teresina, ano 11, n. 1144, 19 ago. 2006. Disponível em: <http://jus.com.br/artigos/8812>. Acesso em: 01 maio2015.

BRASIL. Constituição Federal de 1988. Promulgada em 5 de outubro de 1988. Disponível em <http://www.planalto.gov.br/ccivil_03/constituicao/constituição.htm>. Acesso em: 20 set. 2015.

Código Tributário Nacional. Lei n. ${ }^{\circ}$ 5.172, de 25 de outubro de 1966. Dispõe sobre o Sistema Tributário Nacional e institui normas gerais de direito tributário aplicáveis à União, Estados e Municípios. Diário Oficial da República Federativa do Brasil. Brasília, DF, 25 out. 1966. Disponível em: <http://www.planalto.gov.br/ccivil_03/Leis/L5172.htm> Acesso em: 21 abr. 2015.

Lei Complementar $\mathrm{n}^{\circ}$ 101, de 04 de maio de 2000. Estabelece normas de finanças públicas voltadas para a responsabilidade na gestão fiscal e dá outras providências. Diário Oficial da República Federativa do Brasil, Fortaleza, CE, de 05 de maio de 2000. Disponível em: < http://www.planalto.gov.br/ccivil_03/Leis/LCP/Lcp101.htm> Acesso em: 10 abr. 2015.

Lei $n^{\circ}$. 4.320, de 17 de março de 1964. Estatui Normas Gerais de Direito Financeiro para elaboração e controle dos orçamentos e balanços da União, dos Estados, dos Municípios e do Distrito Federal. Diário Oficial [da] República Federativa do Brasil. Brasília, DF, 17 mar. 1964. Disponível em: <http://www.planalto.gov.br/CCivil_03/leis/L4320.htm> Acesso em: 10 maio 2015.

. Secretaria do Tesouro Nacional. Portaria no . 634, de 19 de novembro de 2013. Dispõe sobre regras gerais acerca das diretrizes, normas e procedimentos contábeis aplicáveis aos entes da Federação, com vistas à consolidação das contas públicas da União, dos Estados, do Distrito Federal e dos Municípios, sob a mesma base conceitual. Disponível em:

http://www3.tesouro.gov.br/legislacao/download/contabilidade/Portaria_STN_634_2013_ Pro cesso_Convergencia.pdf> Acesso em: 10 abr. 2015.

Secretaria do Tesouro Nacional. Portaria no $\mathbf{.}$ 184, de 25 de agosto de 2008.

Dispõe sobre as diretrizes a serem observadas no setor público quanto aos procedimentos, práticas, elaboração e divulgação das demonstrações contábeis, de forma a torná-las vergentes com as Normas Internacionais de Contabilidade Aplicadas ao Setor Público. Disponível em: http://www3.tesouro.gov.br/legislacao/download/contabilidade/Portaria_STN_184_2008_ Pro cesso_Convergencia.pdf> Acesso em: 20 abr. 2015. 
Secretaria do Tesouro Nacional. IPC 02 - Reconhecimento dos Créditos

Tributários pelo Regime de Competência, 2013. Reúne conceitos e procedimentos para os registros patrimoniais, mais especificamente, dos créditos tributários de acordo com os conceitos relacionados à Contabilidade Aplicada ao Setor Público (CASP). Disponível em: http://www.tesouro.fazenda.gov.br/> Acesso em: 20 abr. 2015.

Conselho Federal de Contabilidade. Resolução CFC n' 1.131, de 02 de abr de 2013. Aprova a NBC T 16.4 - Transações no Setor Público. Disponível em: <http://www.cfc.org.br>. Acesso em: 12 dez. 2015.

Conselho Federal de Contabilidade. Resolução CFC n⿳ 1.282, de 02 de junho de 2010. Atualiza e consolida dispositivos da Resolução CFC n. ${ }^{\circ}$ 750/93, que dispõe sobre os Princípios Fundamentais de Contabilidade. Disponível em: <http://www.cfc.org.br>. Acesso em: 30 dez. 2015.

Conselho Federal de Contabilidade. Resolução CFC no 750, de 29 de dezembro de 1993. Dispõe sobre os Princípios de Contabilidade. Disponível em:

<http://www.cfc.org.br>. Acesso em: 12 dez. 2015.

CARVALHO, P. B. Curso de direito tributário. 25. ed. São Paulo: Saraiva, 2013.

CEARÁ. Instrução Normativa $n^{\circ} 01$, de 16 de janeiro de 2014 . Estabelece o prazo para adoção das normas de contabilidade do Setor Público. Tribunal de Contas dos Municipios do Ceará. Disponível em: $<$ http://www.aspec.com.br/novidades/noticias/item/147-tcm-ce-prazoado\%C3\%A7\%C3\% A3o-normas-contabilidade-setor-p\%C3\%BAblico>. Acesso em: 17 dez.

2015 .

CRUVINEL, D. P.; LIMA, D. V. Adoção do regime de competência no setor público brasileiro sob a perspectiva das normas brasileiras e internacionais de Contabilidade. Revista de Educação e Pesquisa em Contabilidade (REPEC), v. 5, n. 3, p. 69-85, 2011.

DARÓS, L. L.; PEREIRA, A. S. Análise das normas brasileiras de contabilidade aplicadas ao setor público: mudanças e desafios para a contabilidade pública. In. Congresso USP de Iniciação Científica, 6, 2009.São Paulo: USP, 2009.Disponível em: <http://www.congressousp.fipecafi.org/artigos92009/467.pdf>. Acesso em: 20 jun. 2015.

FEIJÓ, P. H. Entendendo as mudanças: na contabilidade aplicada ao setor público. 1.ed. Brasília: Gestão Pública Editora, 2013.

FERNANDES, E. C. Direito tributário municipal. V. 1,1. ed. Curitiba: Juruá Editora, 2002.

FORTALEZA. Lei Complementar n 159, de 23 de dezembro de 2013 Institui o Código Tributário do Município de Fortaleza e dá outras providências. Diário Oficial do Município de Fortaleza, Fortaleza, CE, de 27 de dezembro de 2013. Disponível em: < http://legislacao.fortaleza.ce.gov.br/> Acesso em: 17 jan. 2016.

GIL, A. C. Como elaborar projetos de pesquisa. 5. ed. São Paulo: Atlas, 2010.

HARADA, K. O sujeito passivo do IPTU. In: Âmbito Jurídico, Rio Grande, XV, n. $102,2012$.

LIMA, D. V.; SANTANA, C. M.; GUEDES, M. A. As normas brasileiras de contabilidade aplicadas ao setor público e a legislação contábil pública brasileira: uma 
análise comparativa à luz da teoria contábil. Revista Contabilidade e Governança. Brasília, v. 12, n. 2, p. 15 - 23, mai/ago. 2009.

MACHADO, H. B. Comentários ao código tributário nacional. V. I, São Paulo: Atlas, 2014.

MARION, J. C. Análise das demonstrações contábeis. 4. ed. São Paulo: Atlas, 2009.

MARTINS, G. A. Metodologia da investigação cientifica para as ciências sociais aplicadas. 2. ed. São Paulo: Atlas, 2009.

NACIONAL, Secretaria do Tesouro. Manual de contabilidade aplicada ao setor público: aplicado à União, aos Estados, ao Distrito Federal e aos Municípios: Vol. II Procedimentos contábeis patrimoniais. 6. ed. Brasília: Secretaria do Tesouro Nacional, Coordenação-Geral de Contabilidade. Disponível em

<http://www.orcamentofederal.gov.br/biblioteca/arquivos-mcasp/mcasp_6edicao.pdf > Acesso em: 20 set. 2015.

RAUPP, F. M.; BEUREN, I. M. Metodologia da pesquisa aplicável às ciências sociais. Como elaborar trabalhos monográficos em contabilidade. 3. ed. São Paulo: Atlas, 2010.

REIS, H. C. Regime de caixa ou de competência: eis a questão. Revista de Administração Municipal. Rio de Janeiro, v. 52, n. 260, p. 37-48, out./dez., 2006. Disponível em: <http://www.oim.tmunicipal.org.br/abre_documento.cfm?arquivo=_repositorio/_oim/_docum 14 entos/4529D07C-0F29-3F8B-

9850EEADDC99B4D217122008103654.pdf\&i=268>. Acesso em 16 de set de 2015

RIBEIRO FILHO, J.F. 2009. Normas Internacionais de Contabilidade e Princípio de Competência no Setor Público. In: CONVENÇÃO DE CONTABILIDADE DO RIO GRANDE DO SUL, 12, Bento Gonçalves. Disponível em: <www.crcrs.org.br/xii_convencao/jose_francisco_ribeiro.pdf.> Acesso em: 15 mar. 2015. SÖTHE, A.; SCARPIN, J. E. Estudo n 14 do IFAC: impactos na implementação do regime

de competência no governo municipal de Iporã do Oeste - SC. In: $10^{\circ}$ Congresso USP de Controladoria e Contabilidade. 2010. Disponível em $<$ http://www.congressousp. fipecafi.org/artigos102010/290.pdf > Acesso em 20 set 2015.

SOUSA, R. G. et al. O regime de competência no setor público brasileiro: uma pesquisa empírica sobre a utilidade da informação contábil. Revista Contabilidade \& Finanças. São Paulo, v. 24, n. 63, p. 219-230, dez. 2013. ISSN 1808-057X. Disponível em: <http://www.revistas.usp.br/rcf/article/view/78833>. Acesso em: 25 ago. 2015

YIN, R. K. Estudo de caso: planejamento e métodos. 4. ed. Porto Alegre.Bookman, 2010.

ZARTH, S. B.; A aplicação integral do regime de competência na contabilidade pública brasileira segundo as normas brasileiras de contabilidade aplicadas ao setor público.

Revista de Negócios. Porto Alegre. n. 9, p.1-28, março de 2010. 